EESTI NSV TEADUSTE AKADEEMIA TOIMETISED 1955. IV kd., nr. I ИЗВЕСТИЯ АКАДЕМИИ НАУК ЭСТОНСКОИ ССР 1955. ТОМ IV, № 1

\title{
СОДЕРЖАНИЕ ВИТАМИНА С В КАРТОФЕЛЕ И В НЕКОТОРЫХ ОВОЩАХ
}

\author{
Э. П. ВАГАНЕ, \\ кандидат фармацевтических наук
}

э. ю. ТРУУС

В Советском Союзе вопросам организации питания на научно-гигиенических основах придается большое значение, как мощному средству оздоровления населения и поднятия его трудоспособности.

При недостатке витаминов, гиповитаминозе, снижается физическая и умственная трудоспособность человека, организм становится восприимчивым к различным инфекционным заболеваниям. Развитие С-гиповитаминоза у человека наблюдается чаще, чем другие гиповитаминозы, особенно в условиях умеренного и полярного климата.

Из проведенных нами в Таллине исследований выясняется, что во второй половине лета, осенью и в начале зимы (с августа по декабрь) в нашем обычном пищевом рационе имеется достаточно витамина $\mathrm{C}$, чтобы удовлетворить даже такую высокую потребность в нем, как у беременных и кормящих грудью матерей. Но недостаток витамина может проявиться в конце зимы, весной и ранним летом, а в особенности в течение марта, апреля, мая и июня. В случае повышенного расходования витамина С (беременные, кормящие грудью матери, больные и т. п.) недостаток витамина С наблюдается с января по июль, то есть в течение семи месяцев $\left({ }^{2}\right)$. Таким образом, удовлетворение потребности организма в витамине С в Эстонгкой ССР труднее осуществимо, чем, например, в южных братских республиках.

Из источников витамина С в Эстонской ССР наибольшее значение имеют картофель и овощи - капуста, брюква и другие. Фрукты и ягоды в качестве источников витамина имеют здесь меньшее значение ввиду их малого потребления и кратковременности сезона.

По экспериментальным данным, содержание витамина С в овощах существенно зависит от различных условий внешней среды. Одним из наиболее важных факторов внешней среды является свет $\left({ }^{7}\right)$. На содержание витамина $\mathrm{C}$ влияют также температура, влажность почвы, осадки и в некоторой степени удобрение $(3,5,7)$, но в значительно меньшей мере. Несмотря на сильное влияние окружающей среды на витаминность овощей, сортовые различия по содержанию витамина С не теряют своего значения $\left({ }^{3}\right)$. Длительность северного летнего дня, вероятно, является фактором, способствующим накоплению витамина С в овощах, хотя температурные и другие условия на севере хуже, чем на юге. 
По данным Прокошева, в картофеле, выращенном в пригородной зоне Ленинграда и убранном в зрелом состоянии, содержание витамина С составляло в течение первой недели после уборки 19,2-30,6 мг\%, в среднем 24,3 мг\%. Картофель, выращенный под Москвой, содержал витамина С в начале октября $16,8-35,6$ мг\%, в среднем 22,7 мг\%. Несмотря на резкие различия во внешних условиях (почвенные, климатические и экологические), в характере агротехники и сортовом составе картофеля, сходные данные (в среднем 20-30 мг\%) были получены в отношении картофеля, выращенного в Англии, Германии, Голландии, Норвегии и в США $\left.{ }^{5}\right)$. Таким образом, среднее содержание витамина С в картофеле вскоре после уборки составляет $20-30$ мг\%. Прокошев считает пределами изменчивости содержания витамина С в картофеле 5-40 мг\%. Нижний предел характерен для старых, длительно хранившихся клубней, а верхний свойственен молодым клубням.

При хранении картофеля содержание витамина С в нем быстро понижается: за первые три месяца хранения (октябрь-декабрь) это понижение составляет $30-50 \%$, а в следующие три месяца (январь-март) происходит понижение еще на $10-30 \%$. Таким образом, за шесть месяцев теряется около $50-70 \%$ исходного содержания витамина С. Наиболее сильно понижается содержание витамина С в первые дни после уборки $\left({ }^{5}\right)$. Снижение содержания витамина С в клубнях происходит при любых условиях хранения картофеля, но в менее благоприятных условиях хранения картофель за 10 дней может потерять до $50 \%$ витамина С $\left(^{8}\right)$. Картофель желательно хранить при температуре от 1 до $3^{\circ}$. При более низкой температуре $\left(0^{\circ}\right)$ витамин С некоторое время сохраняется лучше, но сам картофель быстрее портится. Относительная влажность воздуха при хранении должна быть $80-85 \%\left({ }^{6}\right)$. Весной происходит небольшое повышение содержания витамина С в картофеле, связанное с прорастанием клубней $\left({ }^{5}\right)$.

Средним содержанием витамина С в капусте и брюкве считается 30 мг\% ( $\left.{ }^{4}\right)$. По данным Букина, капуста после 6-месячного хранения содержала $60-90 \%$ первоначального количества витамина С. Более стойкие сорта теряют меньше витамина, чем менее стойкие сорта ( $\left.{ }^{1}\right)$. Капусту следует хранить при температуре от $0^{\circ}$ до $+1^{\circ}$ и при относительной влажности воздуха $90-95 \%\left({ }^{6}\right)$. При хранении брюквы не наблюдалось такой заметной потери витамина $\mathrm{C}$, как при хранении картофеля $\left.{ }^{1}\right)$.

До настоящего времени не было данных о содержании витамина С в картофеле и в овощах, выращиваемых в Эстонской ССР. Поэтому перед нами стояла задача выяснить содержание витамина $C$ в картофеле и в наиболее распространенных в республике овощах - капусте и брюкве в разные времена года.

Работа проводилась в 1950-1952 годах. В 1950 году материал для исследований был получен с опытных полей филиала Куузику Института растениеводства Академии наук Эстонской ССР. На содержание витамина С было исследовано пять наиболее распространенных в республике сортов картофеля (Фрюботе, Йгеваский желтый, Калев, Мажестик и Остботе), три сорта капусты (Амагер, Энкхуйцен и Элита белорусская) и один сорт брюквы (Красносельская). Уборка картофеля производилась в середине сентября; в августе проводились исследования еще не вполне созревших клубней. Қартофель хранился зимой в бетонированном подвале в закромах, при температуре около $+2^{\circ}$. Капуста и брюква хранились в хранилище при температуре от 0 до $+4^{\circ}$.

В 1951 году материал для исследований был получен с опытных полей Иыгеваской государственной селекционной станцин. Исследованию на содержание витамина С подвергались упомянутые выше пять сортов кар- 
тофеля. Уборку картофеля производили в начале октября, сохраняли его в хранилище под домом зимой при температуре от 1 до 5 градусов.

Содержание витамина С определялось по методике, выработанной Государственной витаминной контрольной станцией Министерства здравоохранения CССР $\left({ }^{4}\right)$. В картофеле мы определяли как $l$-аскорбиновую киелоту, так и дегидроаскорбиновую кислоту; в капусте и брюкве только $l$-аскорбиновую кислоту. Из урожая 1950 года исследовались ежемесячно по 10 клубней каждого сорта картофеля, 3-5 кочанов капусты каждого сорта (три анализа на кочан) и 5 брюкв (по три анализа). Урожай картофеля 1951 года за период хранения исследовался четыре раза (в октябре, декабре, марте и июне) по 10 клубней каждого сорта. Всего содержание витамина С было определено в 960 клубнях картофеля, 50 кочанах капусты и в 30 брюквах.

Результаты исследований (табл. 1 и 2) показывают, что свежий картофель является прекрасным источником витамина С. В августе в свежих клубнях картофеля содержится 26-37 мг\% (в среднем 30 мг\%) витамина С. После уборки, в сентябре-октябре, содержание витамина С в картофеле составляет 19-35 мг\% (в среднем 25 мг\%).

Таблица 1

Содержание витамина С в картофеле, выращенном в Куузику

\begin{tabular}{|c|c|c|c|c|c|c|c|c|c|}
\hline \multirow{2}{*}{ Год } & \multirow{2}{*}{\multicolumn{2}{|c|}{ Месяц }} & \multicolumn{5}{|c|}{$\begin{array}{c}\text { Содержание витамина С в сортах } \\
\text { картофеля в мг \% }\end{array}$} & \multirow{2}{*}{$\begin{array}{l}\text { Среднее } \\
\text { в мг } \%\end{array}$} & \multirow{2}{*}{$\begin{array}{c}\text { Средняя } \\
\text { ошибка } \\
\text { арифмети- } \\
\text { ческого } \\
\text { среднего }\end{array}$} \\
\hline & & & Фрюботе & $\begin{array}{c}\text { Йыгева- } \\
\text { ский } \\
\text { желтый }\end{array}$ & Калев & Мажестик & $\begin{array}{l}\text { Ост- } \\
\text { боте }\end{array}$ & & \\
\hline \multirow[t]{5}{*}{1950} & Август & $\begin{array}{l}a \\
\sigma\end{array}$ & $\begin{array}{l}28,2 \\
24,1\end{array}$ & $\begin{array}{l}36,8 \\
32,1\end{array}$ & $\begin{array}{l}26,4 \\
22,5\end{array}$ & $\overline{-}$ & $\begin{array}{l}30,3 \\
24,4\end{array}$ & $\begin{array}{l}30,4 \\
25,8\end{array}$ & $\begin{array}{l} \pm 2,27 \\
\pm 2,15\end{array}$ \\
\hline & Сентябрь & $\begin{array}{l}a \\
6\end{array}$ & $\begin{array}{l}22,6 \\
21,5\end{array}$ & $\begin{array}{l}34,9 \\
32,0\end{array}$ & $\begin{array}{l}23,4 \\
21,1\end{array}$ & $\begin{array}{l}19,1 \\
17,5\end{array}$ & $\begin{array}{l}32,5 \\
28,0\end{array}$ & $\begin{array}{l}26,5 \\
24,0\end{array}$ & $\begin{array}{l} \pm 2,30 \\
\pm 2,61\end{array}$ \\
\hline & Октябрь & $\begin{array}{l}a \\
\sigma\end{array}$ & $\begin{array}{l}17,9 \\
17,3\end{array}$ & $\begin{array}{l}25,3 \\
22,8\end{array}$ & $\begin{array}{l}18,7 \\
16,1\end{array}$ & $\begin{array}{l}12,9 \\
11,1\end{array}$ & $\begin{array}{l}23,4 \\
19,1\end{array}$ & $\begin{array}{l}19,6 \\
17,3\end{array}$ & $\begin{array}{l} \pm 2,18 \\
\pm 1,91\end{array}$ \\
\hline & Ноябрь - & $\begin{array}{l}a \\
\sigma\end{array}$ & $\overline{14,7}$ & $\overline{15,7}$ & $\overline{14,0}$ & $\overline{10,0}$ & $\overline{18}, 0$ & $\overline{14,5}$ & $\pm \overline{1}, 30$ \\
\hline & Декабрь & $\frac{a}{b}$ & $\overline{12,8}$ & $\overline{11,5}$ & $\overline{14,1}$ & $\overline{7,6}$ & $\overline{13}, 3$ & $\overline{11,9}$ & $\pm \overline{1,14}$ \\
\hline \multirow[t]{7}{*}{1951} & Январь & $\begin{array}{l}a \\
\sigma\end{array}$ & $\overline{10,8}$ & $\overline{7,1}$ & $\overline{11,9}$ & $\overline{7,7}$ & $\overline{11}, 4$ & $\overline{9,8}$ & $\pm \overline{0}, 99$ \\
\hline & Февраль & $\begin{array}{l}a \\
\sigma\end{array}$ & $\overline{12,6}$ & $\overline{7,1}$ & $\overline{10,9}$ & $\overline{7,5}$ & $\overline{8}, 0$ & $\overline{9,2}$ & $\pm \overline{1,07}$ \\
\hline & Март & $\begin{array}{l}a \\
\sigma\end{array}$ & $\begin{array}{r}10,4 \\
9,7\end{array}$ & $\begin{array}{l}9,8 \\
6,1\end{array}$ & $\begin{array}{r}13,5 \\
9,8\end{array}$ & $\begin{array}{l}7,7 \\
4,6\end{array}$ & $\begin{array}{r}10,0 \\
6,0\end{array}$ & $\begin{array}{r}10,3 \\
7,2\end{array}$ & $\begin{array}{l} \pm 0,93 \\
\pm 1,07\end{array}$ \\
\hline & Апрель & $\begin{array}{l}a \\
\sigma\end{array}$ & $\begin{array}{l}9,1 \\
8,5\end{array}$ & $\begin{array}{l}7,1 \\
4,7\end{array}$ & $\begin{array}{r}10,7 \\
8,3\end{array}$ & $\begin{array}{l}7,6 \\
4,2\end{array}$ & $\begin{array}{r}11,6 \\
7,2\end{array}$ & $\begin{array}{l}9,2 \\
6,6\end{array}$ & $\begin{array}{l} \pm 0,87 \\
\pm 0,90\end{array}$ \\
\hline & Май & $\begin{array}{l}a \\
\sigma\end{array}$ & $\begin{array}{l}9,1 \\
8,8\end{array}$ & $\begin{array}{l}8,2 \\
4,8\end{array}$ & $\begin{array}{r}10,5 \\
7,7\end{array}$ & $\begin{array}{l}7,9 \\
4,4\end{array}$ & $\begin{array}{l}8,3 \\
4,6\end{array}$ & $\begin{array}{l}8,8 \\
6,1\end{array}$ & $\begin{array}{l} \pm 0,47 \\
\pm 0,91\end{array}$ \\
\hline & Июнь & $\begin{array}{l}a \\
\sigma\end{array}$ & $\begin{array}{l}6,9 \\
6,4\end{array}$ & $\begin{array}{l}6,9 \\
6,6\end{array}$ & $\begin{array}{l}7,0 \\
6,3\end{array}$ & $\begin{array}{l}8,6 \\
5,6\end{array}$ & $\begin{array}{l}8,6 \\
6,0\end{array}$ & $\begin{array}{l}7,6 \\
6,2\end{array}$ & $\begin{array}{l} \pm 0,41 \\
\pm 0,17\end{array}$ \\
\hline & Июль & $\begin{array}{l}a \\
\sigma\end{array}$ & $\begin{array}{l}7,9 \\
6,2\end{array}$ & $\begin{array}{l}7,8 \\
6,1\end{array}$ & $\begin{array}{l}9,2 \\
7,6\end{array}$ & $\begin{array}{l}8,0 \\
5,2\end{array}$ & $\begin{array}{l}6,9 \\
5,1\end{array}$ & $\begin{array}{l}8 ; 0 \\
6,0\end{array}$ & $\begin{array}{l} \pm 0,37 \\
\pm 0,45\end{array}$ \\
\hline
\end{tabular}

$a=l$-аскорбиновая кислота + дегидроаскорбнновая кислота

$\sigma=l$-аскорбиновая кислота 
Содержание витамина С в картофеле, выращенном в Иыгева

\begin{tabular}{|c|c|c|c|c|c|c|c|c|}
\hline \multirow{2}{*}{ Год } & \multirow{2}{*}{ Месяц } & \multicolumn{5}{|c|}{$\begin{array}{c}\text { Содержание витамина С в сортах } \\
\text { картофеля в мг \% }\end{array}$} & \multirow{2}{*}{$\begin{array}{l}\text { Среднее } \\
\text { в мг \% }\end{array}$} & \multirow{2}{*}{$\begin{array}{c}\text { Средняя } \\
\text { ошибка } \\
\text { арифмети- } \\
\text { ческого } \\
\text { среднего }\end{array}$} \\
\hline & & Фрюботе & $\begin{array}{c}\text { Йыгева- } \\
\text { скнй } \\
\text { желтый }\end{array}$ & Калев & Мажестик & $\begin{array}{l}\text { Ост- } \\
\text { боте }\end{array}$ & & \\
\hline \multirow[t]{2}{*}{1951} & Октябрь & $\begin{array}{l}24,7 \\
21,0\end{array}$ & $\begin{array}{l}25,0 \\
18,7\end{array}$ & $\begin{array}{l}26,6 \\
23.0\end{array}$ & $\begin{array}{l}20,5 \\
14,7\end{array}$ & $\begin{array}{l}28,6 \\
19,2\end{array}$ & $\begin{array}{l}25,1 \\
19,3\end{array}$ & $\begin{array}{l} \pm 1,34 \\
\pm 1,25\end{array}$ \\
\hline & Декабрь & $\begin{array}{l}17,5 \\
16,1\end{array}$ & $\begin{array}{l}16,3 \\
13,5\end{array}$ & $\begin{array}{l}22,3 \\
17,1\end{array}$ & $\begin{array}{r}12,2 \\
9,2\end{array}$ & $\begin{array}{l}19,8 \\
11,4\end{array}$ & $\begin{array}{l}17,6 \\
13,5\end{array}$ & $\begin{array}{l} \pm 1,70 \\
\pm 0,79\end{array}$ \\
\hline \multirow[t]{2}{*}{1952} & Март & $\begin{array}{r}12,0 \\
9,7\end{array}$ & $\begin{array}{l}8,2 \\
4,5\end{array}$ & $\begin{array}{l}14,0 \\
13,0\end{array}$ & $\begin{array}{l}9,2 \\
5,3\end{array}$ & $\begin{array}{r}12,5 \\
5,9\end{array}$ & $\begin{array}{r}11,2 \\
7,7\end{array}$ & $\begin{array}{l} \pm 1,08 \\
\pm 1,60\end{array}$ \\
\hline & Июнь & $\begin{array}{l}7,4 \\
5,7\end{array}$ & $\begin{array}{l}8,6 \\
3,7\end{array}$ & $\begin{array}{l}11,6 \\
10,5\end{array}$ & $\begin{array}{l}7,7 \\
5,6\end{array}$ & $\begin{array}{l}8,1 \\
6,5\end{array}$ & $\begin{array}{l}8,7 \\
6,4\end{array}$ & $\begin{array}{l} \pm 0,75 \\
\pm 1,12\end{array}$ \\
\hline
\end{tabular}

$\boldsymbol{a}=\boldsymbol{l}$-аскорбиновая кислота + дегидроаскорбиновая кислота

$\sigma=l$-аскорбиновая кислота

По данным Прокошева, средняя норма пищевого потребления картофеля на человека в Советском Союзе составляет 300 г в сутки $\left(^{5}\right)$. Учитывая потери витамина С при кулинарной обработке картофеля (при варке около 25\%), - 300 г картофеля могут в августе-октябре полностью удовлетворить минимальную потребность человека в витамине С (50 мг в сутки).

При хранении картофеля содержание витамина С быстро падает и к декабрю остается половина, а к весне всего лишь четверть (около 8 мг\%) летнего содержания. Весной и ранним летом 300 г вареного картофеля содержат около 20 мг вита́мина С. Это количество витамина $\mathrm{C}$ предохраняет человека от цынги, но далеко не удовлетворяет его потребности в витамине.

Сорта картофеля, отличающиеся высоким содержанием витамина С осенью (Остботе, Йгеваский желтый), в начальный период хранения теряют больше витамина, чем сорта с более низким содержанием его (Мажестик), вследствие чего содержание витамина С в разных сортах картофеля к весне уравнивается.

Количество дегидроаскорбиновой кислоты в картофеле в течение всего периода хранения колеблется в среднем в пределах $1,4-5,8$ мг\%. Накапливания дегидроаскорбиновой кислоты в картофеле при хранении не

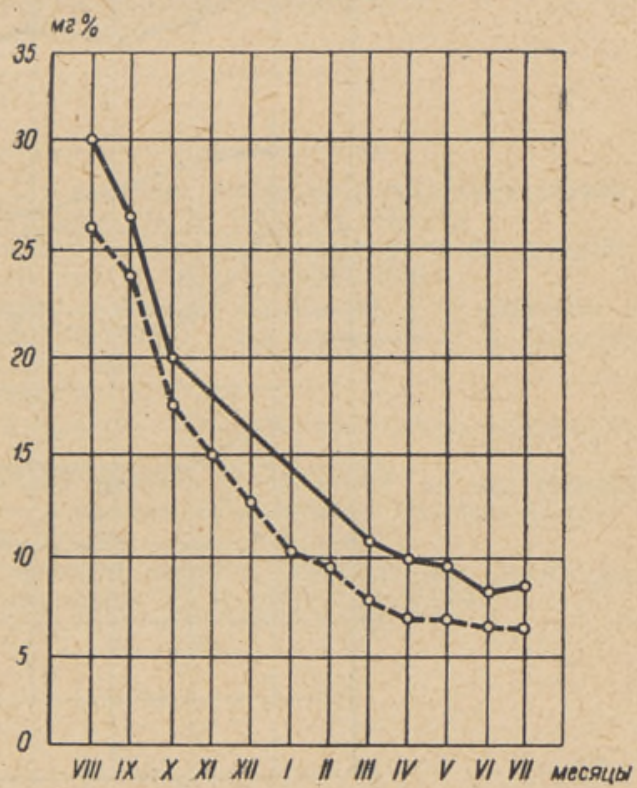

Рнс. 1. Содержание-витамннов С в картофеле, выращенном в Куузику в 1950 г. $l$-аскорбиновая кислота + дегидроаскорбиновая кислота, ... $l$-аскорбиновая кислота. 
наблюдается (рис. 1). Возможно, что часть дегидроаскорбиновой кислоты образуется лишь в ходе определения, вследствие окисления аскорбиновой кислоты.

Таблица 3

Содержание витамина С в капусте и в брюкве, выращенных в Куузику

\begin{tabular}{|c|c|c|c|c|c|}
\hline \multirow{3}{*}{ Год } & \multirow{3}{*}{ Месяц } & \multicolumn{4}{|c|}{ Содержание витамина С в мг\% } \\
\hline & & \multicolumn{3}{|c|}{ в сортах капусты } & \multirow{2}{*}{$\begin{array}{l}\text { в брюкве } \\
\text { Красно- } \\
\text { сельская }\end{array}$} \\
\hline & & Амarep & $\begin{array}{c}\text { Элита } \\
\text { белорусская }\end{array}$ & Энкхуйцен & \\
\hline \multirow[t]{2}{*}{1950} & Ноябрь & 52 & 40 & 35 & 23 \\
\hline & Декабрь & 48 & 39 & 29 & 20 \\
\hline \multirow[t]{5}{*}{1951} & Январь & 47 & - & - & 19 \\
\hline & Февраль & 48 & 36 & 29 & 20 \\
\hline & Март & - & 37 & - & 18 \\
\hline & Апрель & 44 & 32 & - & - \\
\hline & Май & - & - & - & 17 \\
\hline
\end{tabular}

Из таблицы 3 и рис. 2 видно, что хорошими источниками витамина $\mathrm{C}$ являются также капуста и брюква. В капусте содержится в ноябре 3552 мг\% витамина С, особенно много его в позднем сорте Амагер. После

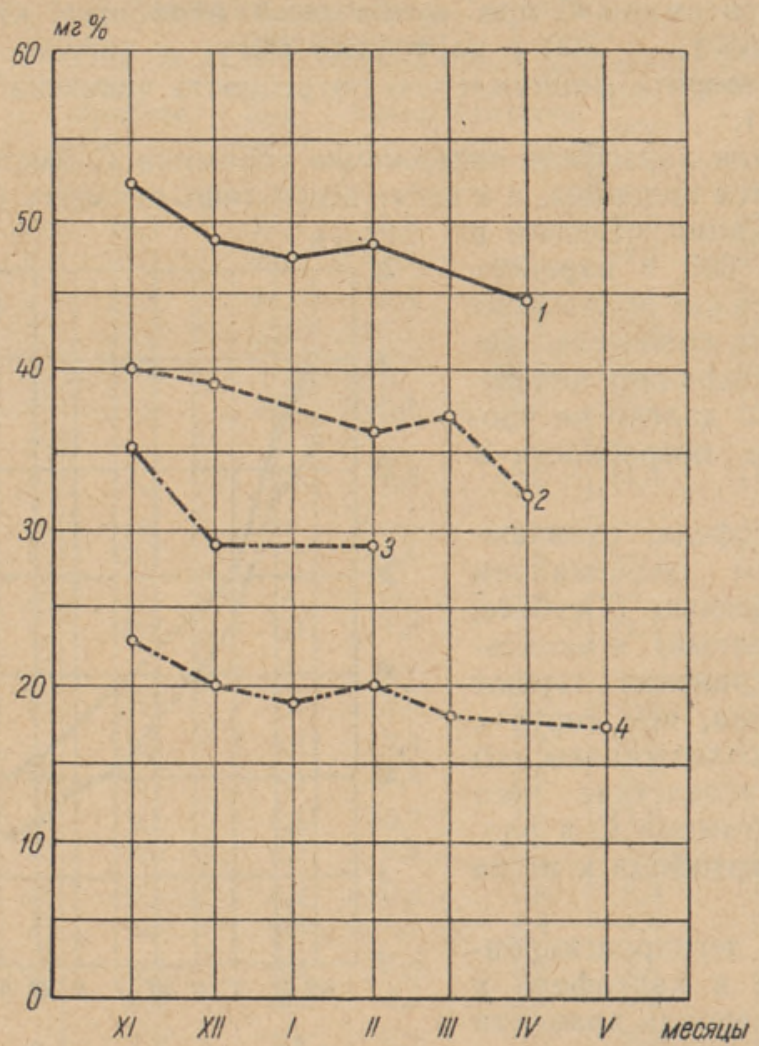

Рис. 2. Содержание витамина $\mathrm{C}$ в капусте и брюкве, выращенных в Куузику в 1950 г. Капуста: 1 Амагер, 2 - Элита белорусская, 3 - Энкхуйцен.

Брюква: 4 - Красносельская. 
уборки во внешних зеленых листьях капусты содержится больше витамина, чем во внутренних, и особенно много его в кочерыжке (6080 мг\%). В брюкве сорта Красносельская содержится около 20 мг\% витамина C.

При хранении в капусте и брюкве не происходит значительного снижения содержания витамина C (за пять месяцев хранения потеря витамина С составляет $15-25 \%$ ). Поэтому капуста и брюква в зимне-весенний период содержат значительно больше витамина С, чем картофель, и имеют в этот период большее значение как источники витамина С.

\section{Выводы}

1. Картофель и озощи, выращиваемые в Эстонской ССР, отличаются осенью высоким содержанием витамина С. Они вполне могут удовлетворить потребность в витамине С во второй половине лета, осенью и в начале зимы. Но зимой, весной и ранним летом в местных условиях может обнаружиться недостаток его, так как в этот период источников витамина становится мало, а наиболее часто употребляемый в пищу картофель уже теряет большую часть витамина С.

2. Для улучшения витаминного питания зимой, весной и ранним летом необходимо увеличить производство и заготовку источников витамина С на зиму. Прежде всего необходимо заготовлять картофель и овощи, потребляемые в пищу в большем количестве, и овощи, хорошо сохраняющие витамин С (капуста и брюква). Летом следует возможно раньше вводить в меню свежий картофель.

Ннститут экспериментальной и клинической медицины Академии наук Эстонской ССР

Поступила в редакцию 22 V 1954

\section{ЛИТЕРАТУРА}

1. В. Н. Бу кин, Витамины, М., 1941.

2. Э. П. В а ган е, Содержание витамина С в грудном молоке по материалам родильных домов Таллина, «Вопросы питания», № 6, 1953, стр. 59-63.

3. О. Н. З о тов а, Влияние некоторых условий выращивания картофеля на содержание витамина С, «Биохимия», т. 18, вып. 2, 1953, стр. 205-209.

4. Методнческое руководство по определению витаминов C, $\mathrm{B}_{1}, \mathrm{D}, \mathrm{A}$ и каротина в пищевых продуктах и витаминных препаратах. Под редакцией Б. А. Лаврова и А. И. Штенберга, 2-е издание, М., 1950.

5. С. М. Прокош е в, Биохимия картофеля, М.-Л., 1947.

6. В. Н. Р учкин, Хранение и основы технологии сельскохозяйственных продуктов, M., 1952.

7. Г. Ф. Сомерс и К. С. Бизон, Влияние климата и удобреннй на содержание витаминов и минеральных веществ в овощах, жБиохимия и физиология внтаминовљ, Сборник 1, М., 1950, стр. 32-61.

8. Л. С. Т а н а тар, Характеристнка витаминной ценности растительных предуктов Одеского района, «Гигиена и санитария», № 6, 1950, стр. 27-30. 